\section{Infection Control and Prevention Programs in Integrated Healthcare Delivery Systems in the Time of Ebola and Enterovirus D68: The Challenge Before Us}

To the Editor-Infection prevention and control has evolved over the last several decades at the hospital level. Today's healthcare environment has fostered the development of 'integrated' healthcare delivery systems, which are expansive in some cases. Unfortunately, integration of different hospitalbased infection control programs lags behind the administrative organizational structure in such systems. Management of a suspect case of Ebola virus infection in a hospital system brings this gap to the limelight. Should such a patient be cared for at one of the healthcare system's designated institutions? How would such a patient showing up at an affiliate institution be isolated until transported to that one facility, and what care would be administered prior to such transport? For example, would intravenous access be obtained at the affiliate institution prior to transport? Would blood work be obtained and/or processed before transfer, would malaria be ruled out before transfer? Would laboratory specimens be processed at one or more facilities within the healthcare system?

Be it Ebola, Enterovirus D68, or the myriad other infection control challenges confronting healthcare systems, who is the final, unequivocally empowered arbiter of systemwide infection control issues? We have learned much from emergency preparedness exercises and past pandemic planning, as with H1N1 for example; however, when push comes to shove, is the line of infection control authority in integrated systems transparent and evident to all involved? A healthcare systemwide infection control and prevention council is a pragmatic approach to organizing such activities. The council should at least have representation of the following individuals from each affiliate: lead infection preventionist/director and hospital epidemiologist (if one exists); chief medical officer; chief nursing officer; director of employee and occupational health for the healthcare system; and director of information technology or chief technology officer for the healthcare system. The council should be chaired by clearly designated director(s) of infection control and prevention for the healthcare system. This arrangement may be most functional as a dyad consisting of a hospital epidemiologist and infection preventionist director. These individuals meet with directors of each affiliate's infection control program to prioritize infection control issues brought to the attention of the council. The council chairs should be empowered to make the final decisions should controversy exist, based on the body of literature on the subject at hand or outside expert opinion should the literature not be sufficient to address the issue. The supporting material for such final decisions should be shared with council members.

As we continue our efforts to maintain a safe and healthy environment for our patients and our staff, and as we do so in a new world order with the disappearance of free-standing hospitals and the development of large networks that are expected to be more efficient in the delivery of care, leaders in infection control need to develop standards and structure for system-wide implementation of best practice as a functional system. The alternative is unacceptable.

\section{ACKNOWLEDGMENTS}

Financial support. There was no financial support for this work. Potential conflicts of interest. The author has no conflicts of interest to report.

Leonard A. Mermel, DO, ScM, AM (Hon), FSHEA, FIDSA, FACP $^{1}$

Affiliations: Department of Epidemiology and Infection Control, Rhode Island Hospital and Department of Medicine, Warren Alpert Medical School of Brown University, Providence, Rhode Island.

Address correspondence to Dr. Leonard Mermel, Division of Infectious Diseases, Rhode Island Hospital, 593 Eddy Street, Providence, RI 02903 (lmermel@lifespan.org).

Received: October 26, 2014; Accepted: November 05, 2014. Infect Control Hosp Epidemiol 2015;36(2):239

(C) 2014 by The Society for Healthcare Epidemiology of America. All rights reserved. 0899-823X/2015/3602-0022. DOI: 10.1017/ice.2014.49 